\title{
Performance evaluation of the grinding wheel with aggregates of grains in grinding of Ti-6Al-4V titanium alloy
}

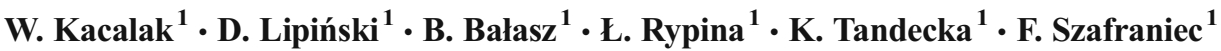

Received: 5 April 2017 / Accepted: 31 July 2017 / Published online: 10 August 2017

(C) The Author(s) 2017. This article is an open access publication

\begin{abstract}
The results of grinding are highly dependent on conditions of workpiece removal process. The material is removed by an unspecified number of abrasive grains of irregular shape and random distribution on the grinding wheel active surface. The interaction between the abrasive grain and the workpiece can be divided into three stages: (i) rubbing, (ii) ploughing and (iii) chip formation. Reciprocal contribution of each stage is dependent on the properties of the workpiece, the grinding parameters, the friction condition between the abrasive grain and the workpiece and the shape of the grains. In the article, the results of numerical and experimental process in the analysis of grinding of Ti-6Al-4V titanium alloy, using a conventional grinding wheel and a newly developed grinding wheel with aggregates of grains, were presented. The analysis of influence of the geometric parameters of the abrasive aggregates and the abrasive grains on the effectiveness of the workpiece removal process is presented. The effects of the geometrical parameters of grains and abrasive aggregates in direction of motion as well as in transversal direction on the size of ridges were determined. It has been observed that increase of the length of sideway material displacement results in the decrease of ridge formation. The results of a numerical analysis were confirmed by experimental research. The analysis of the impact of utilization of abrasive aggregates on the grinding forces, grinding-specific energy and surface roughness was performed. The impact of abrasive aggregates on the decrease of grinding forces and specific
\end{abstract}

D. Lipiński

dariusz.lipinski@tu.koszalin.pl

1 Department of Mechanical Engineering, Koszalin University of Technology, Raclawicka 15-17, 75-620 Koszalin, Poland energy and the increase of quality of ground surface was observed.

Keywords Grinding · Grinding wheel · Grain shape · Titanium alloy $\cdot$ Roughness $\cdot$ Grinding forces

\section{Introduction}

Titanium alloys are widely used particularly in the aerospace and biomedical industry [1-3]. This state is affected by the large number of favourable properties of these alloys [4-6]: high strength-to-weight ratio, biocompatibility, high corrosion and creep resistance, and high strength at elevated temperatures. The properties of titanium alloys, favourable for their applications, often have a negative impact on their machining. Titanium alloys are considered to be difficult-to-cut materials due to their mechanical and physical properties. Difficulties in cutting of Ti-6Al-4V alloy are based on its properties [1, 5]: high chemical activity, low thermal conductivity and susceptibility to form build-up on blade surfaces. The hexagonal $\alpha$ phase of Ti-6Al-4V alloy is hard, fragile and difficult to form and has a tendency to strain hardening. Spatially centred $\beta$ phase has a similar behaviour during cutting to a crystallizing ferrite, as it is easy to form, rather soft and malleable [2, 6]. It also exhibits a strong tendency to adhere to the blade of the tool.

During the machining of titanium alloys, oxides are released, which negatively influence the cutting edge. High temperature in the working zone causes the saturation of the outer surface of the workpiece with oxygen, hydrogen, carbon and nitrogen, causing a decrease of its plasticity [2]. The conducted study on the grinding process of Ti-6Al-4V alloy [7, 8] indicates their elevated chemical activity, which may lead to a strong build-up on abrasive grains. Certain studies [9-11] 
indicated high reactivity of titanium alloys with the tools containing diamond and cubic boron nitride. Increased adhesion between these elements causes a decrease of a tool life [9]. Moreover, both diamond and cubic boron nitride are very expensive abrasive materials. The cost of abrasive tools consisting these materials is approximately several times higher than the cost of abrasive tools with aluminium oxide or silicon carbide grains.

During cutting titanium alloys, the low thermal conductivity of these alloys causes around $15 \%$ of the produced heat to be accumulated on the cutting edge and the cutting tool face [12]. A consequence of high temperature in the workpiece surface layer reaching $1200{ }^{\circ} \mathrm{C}$ is an intensive tool wear and deformation. Blunt edges of the cutting tool produce an increasing amount of heat, shortening its life [13, 14]. Problematics of decreasing the thermal interactions in the cutting zone has been discussed by numerous researchers. Grinding with minimal quantity lubrication (MQL) provides efficient lubrication, reducing the grinding power and specific energy [15-17]. A decrease of thermal interactions in the grinding zone may be also obtained by the proper selection of processing parameters $[18,19]$. In recent years, due to the development of numerical and measurement techniques, numerous attempts are made to a detailed description of the phenomena occurring in the contact zone of the abrasive grain and the workpiece. The interaction between the abrasive grain and the workpiece can be divided into three stages [20]: (i) rubbing, (ii) ploughing and (iii) chip formation. It is favourable to decrease the rubbing and ploughing in the grinding zone and to ensure stable conditions of the cutting process with abrasive grains. Reciprocal contribution of each state is dependent on properties of the workpiece, the grinding parameters, the friction condition between abrasive grain and the workpiece, and the shape of the grains [21,22].

In the following study, the grinding process of titanium alloys using abrasive tools with aggregates of grains was analysed. The modification of the grinding wheel involving inserting aggregates made of abrasive grains with a size less than the abrasive grain size used for the construction of the entire grinding wheel was proposed. The results of carried out studies indicate that the increased number of active grains per grinding wheel active surface results in a decrease of the equivalent chip thickness, thus decreasing the force values in the grinding process. Moreover, the differences in size and mutual distance between the vertexes of abrasive grains included in the abrasive aggregate may result in a different mechanism of material separation in comparison to the mechanism of material separation with a single abrasive grain. As a result, surfaces with reduced roughness were obtained.

Section 3 presents a numerical analysis of the grinding process with abrasive aggregates with the applications of the finite element method. The obtained results were compared to the results of grinding process simulations with a single abrasive grain. Favourable effects of abrasive aggregates resulting from the decreased size of ridges and reduced cross-sections of the layers cut by a single grain were found. Section 4 explains the experiment whose aim was a verification of the conclusions obtained through simulation tests. Tests and analyses of the grinding process were conducted using conventional aluminium oxide grinding wheels and modified grinding wheels with $30 \%$ contribution of abrasive aggregates. Section 5 contains the analysis of the experiment results and its conclusions.

\section{Analysis of the material removal mechanism with abrasive aggregate}

\subsection{Grinding wheel with aggregated grains}

The grinding of titanium alloys is a difficult process due to the high grinding forces, high specific grinding energy as well as due to the filling of the spaces between the grain products of the processing and difficulties in the stabilization of the tool cutting capability. In order to ensure favourable conditions of grinding, providing the process with reduced grinding forces and lower specific energy, the grinding wheels with abrasive aggregates were developed (Fig. 1).

A modified grinding wheel consists of basic aluminium oxide grains (e.g. size $250 \mu \mathrm{m}$ ) and abrasive aggregates larger (e.g. size $355 \mu \mathrm{m}$ ) than basic grains. Abrasive aggregates consist of abrasive grains smaller (e.g. size $106 \mu \mathrm{m}$ ) than the basic grains. SEM images presenting the structure of the produced grinding wheels are shown in Fig. 2.

Figure $2 \mathrm{a}, \mathrm{b}$ presents the grinding wheel active surface. Apart from the basic grains, abrasive aggregates are visible. Figure $2 \mathrm{c}$ presents an example of abrasive aggregate consisting of numerous grinding grains with irregular shape. Contrary to a single abrasive grain (Fig. 2d), an abrasive aggregate contains numerous, closely spaced cutting edges. Distances between abrasive grains in the abrasive aggregate are considerably shorter than the distances between basic abrasive grains.

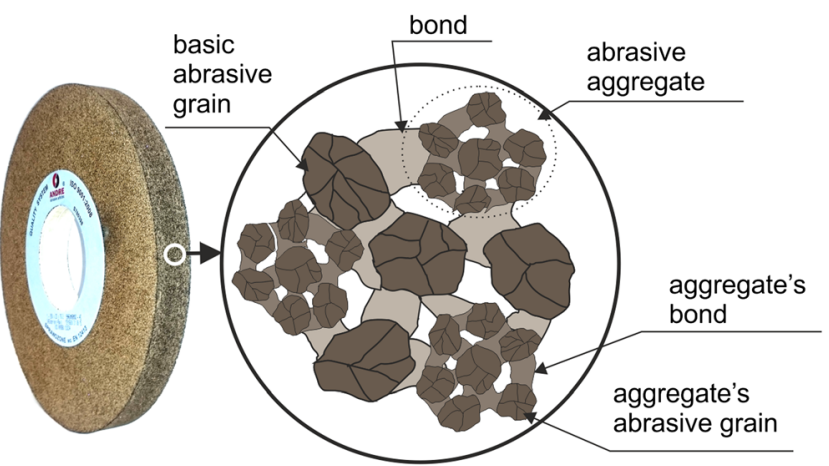

Fig. 1 Structure of the grinding wheel with aggregates 
Fig. 2 SEM images of the grinding wheel: a grinding wheel active surface (magnification $245 \times$ ), b grinding wheel active surface (magnification 390×), c abrasive aggregate (magnification $360 \times)$, and $\mathbf{d}$ abrasive grains (magnification 270×)
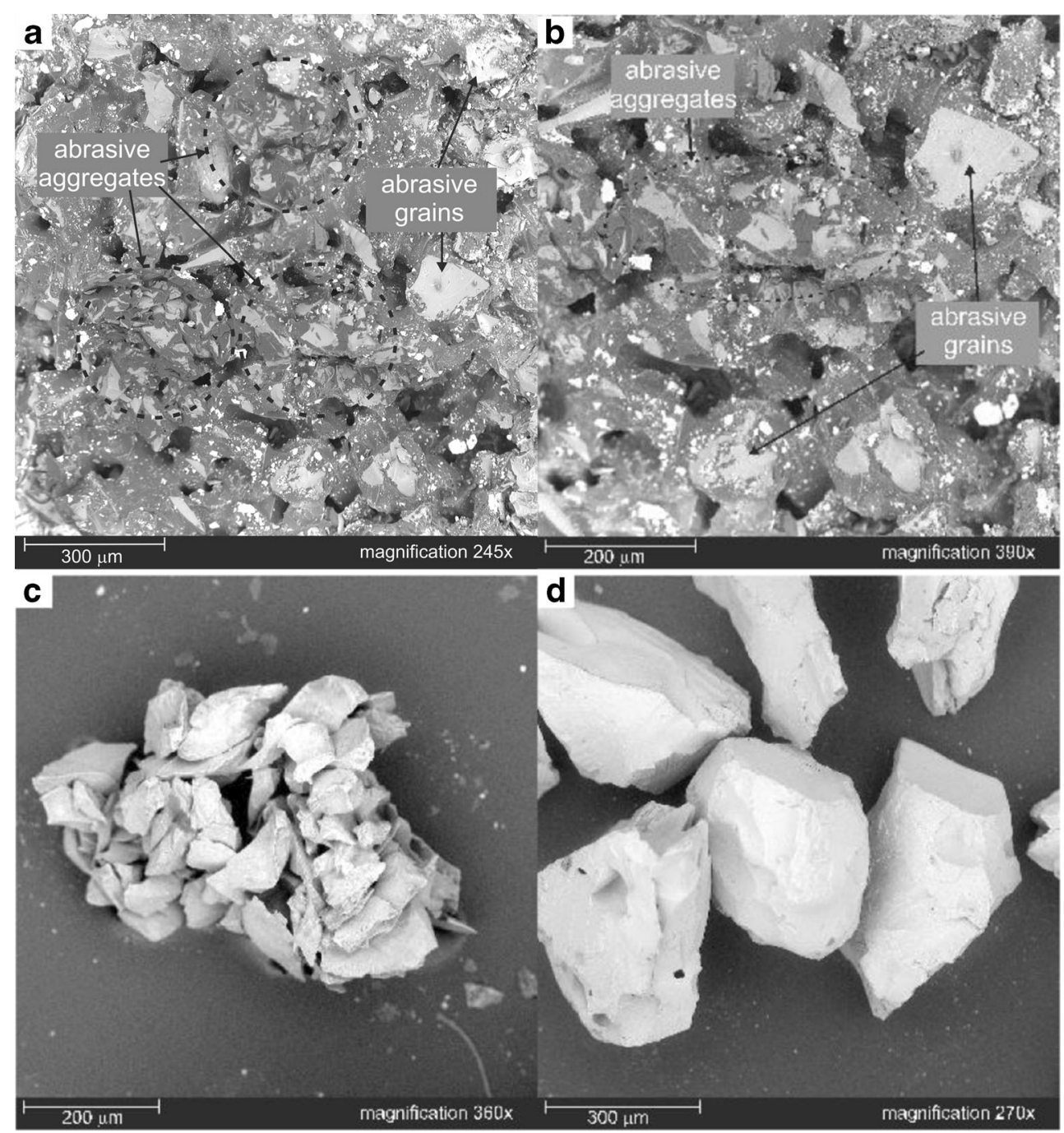

\subsection{Numerical simulation procedure}

The addition of abrasive aggregates may result in a different mechanism of material separation in comparison to the mechanism of material separation with a single abrasive grain. It is possible to obtain a wider grinding zone and the simultaneous interaction of many more abrasive grains in the aggregate with workpiece. FEM studies are helpful in assessing the impact of geometric parameters of grains and aggregates on material removal process. The aim of the FEM simulation was a comparative analysis of geometric parameters of grains and aggregates and their impact on side ridges and chip formation. The analysis of microcutting was conducted using the AUTODYNA solver, which enables conducting of nonlinear and dynamic analyses using the finite element method in a two-dimensional and three-dimensional system. Calculations were preceded by digitization, which enables the division of a complex mathematic model into a smaller number of simplified elements.
The geometry of a sample abrasive grain shape (grain A and grain B) and an abrasive aggregate was used in the process of numerical modelling and simulation. The abrasive grains and the abrasive aggregate were measured using an ATOS III SO scanner. The use of structural light scanner allows for a detailed analysis of the geometric structure of the grinding wheel active surface $[23,24]$. The abrasive grain and abrasive aggregates were modelled as a rigid body, whereas the workpiece as viscoplastic.

Numerical modelling for heavy deformations and high strain rates, which are typical of cutting processes, using the Lagrange method (the object covered with a mesh moving and deforming along with it), was conducted. The modelled abrasive grain, abrasive aggregate and workpiece were digitized with three-dimensional, 8-node elements Solid164 type. In the workpiece, translational and rotational degrees of freedom for the nodes at the base of the material were removed. The abrasive grain and abrasive aggregates were moving lengthwise of the workpiece surface with the speed $v_{\mathrm{c}}=30 \mathrm{~m} / \mathrm{s}$. The 
Table 1 Parameters of the material model used in the simulation [27]

\begin{tabular}{ll}
\hline Property & Ti-6Al-4V \\
\hline$A(\mathrm{MPa})$ & 820 \\
$B(\mathrm{MPa})$ & 220 \\
$n$ & 0.01 \\
$C$ & 0.26 \\
$m$ & 1.01 \\
$T_{\text {melt }}\left({ }^{\circ} \mathrm{C}\right)$ & 1610 \\
$T_{\text {amb }}\left({ }^{\circ} \mathrm{C}\right)$ & 21 \\
\hline
\end{tabular}

workpiece surface was inclined in order to obtain the increased depth of cut.

The Johnson-Cook material model was used in the computer analysis, which refers to the distribution of stress, deformations, deformation rates and temperature in the tested object. Johnson-Cook equations are commonly used for the modelling of materials exposed to deformations in a wide range of deformation rates and temperature $[25,26]$. The general form of the Johnson-Cook equation is as follows [25]:

$\sigma=\left(A+B\left(\varepsilon_{\mathrm{p}}\right)^{n}\right)\left(1+C \times \ln \frac{\dot{\varepsilon}_{\mathrm{p}}}{\dot{\varepsilon}_{0}}\right)\left(1-\left(\frac{T-T_{\mathrm{amb}}}{T_{\text {melt }}-T_{\mathrm{amb}}}\right)^{m}\right)$

where $A$ - initial, static yield strength; $B$ - parameter of plastic strength; $\varepsilon_{\mathrm{p}}$ - effective plastic strain; $n$-exponent of plastic deformation strength; $C$-material parameter specifying the impact of the intensity of plastic speed deformation; $\dot{\varepsilon}_{\mathrm{p}}, \dot{\varepsilon}_{0}$ -effective plastic and reference strain rates; $T, T_{\mathrm{amb}}, T_{\text {melt }}$ - current, ambient and melting temperatures and $m$-exponent of thermal plasticity.

Material properties of the Ti-6Al-4V alloy were used for the numerical model of the workpiece. The parameters of the material model are presented in Table 1.

In order to solve the established problem of determining the influence of geometric parameters of abrasive aggregate and abrasive grain on the directions of the movements of the workpiece material, Verlet integration was used. In this method, the equation explaining the movement of an object can be written as follows:

$\boldsymbol{M} \ddot{\boldsymbol{r}}(\tau)+\boldsymbol{C} \boldsymbol{r}(\tau)+\boldsymbol{K} \boldsymbol{r}(\tau)=\boldsymbol{R}(\tau)$

where $\boldsymbol{M}, \boldsymbol{C}$ and $\boldsymbol{K}$ are the respective constants in time matrices of mass, damping and system stiffness. $\boldsymbol{R}$ expresses the internal load vector, and $\ddot{\boldsymbol{r}}, \boldsymbol{r}$, and $\boldsymbol{r}$ are vectors of displacement, rate and acceleration of nodes of the system.

\subsection{Analysis of numerical simulation results}

The analysis of the results of the microcutting with a single abrasive grain and abrasive aggregate allows to observe differences in the chip formation process (Figs. 3 and 4).

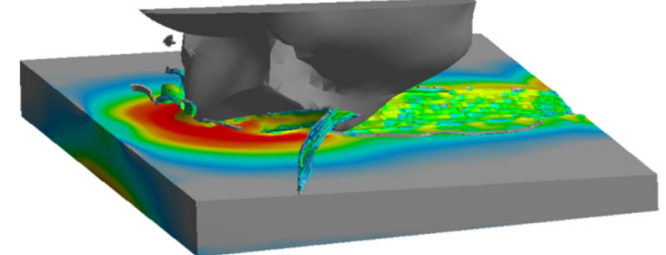

Fig. 3 Visualization of the Ti-6Al-4V alloy cutting with abrasive grain (grain A)

Chips obtained as a result of removing the material with abrasive aggregates are characterized by reduced thickness; they are longer and more numerous. Differences in the size and number of side ridges appearing in the contact zone of the abrasive material with the workpiece are clearly visible. In the case of the abrasive grain, the portion of the material is moved to its sides, producing clearly visible ridges. In the case of the abrasive aggregate for low values of penetration in the material, many small side ridges are formed by single grains of aggregate in the contact zone. Along with the increment of abrasive aggregate penetration, the movement of the material to the sides becomes more difficult due to the wide aggregate's contact zone. As a consequence, side ridges are visible only on the sides of the contact zone. The geometric parameters of abrasive grain and abrasive aggregate influence such a mechanism of material separation.

The analysis of the geometric parameters of abrasive grains and aggregate for the variable value of penetration $h$ ( $h_{1}=5 \mu \mathrm{m}, h_{2}=10 \mu \mathrm{m}, h_{3}=15 \mu \mathrm{m}, h_{4}=20 \mu \mathrm{m}$ ) into the workpiece was conducted. The geometry of the abrasive grains and aggregate was analysed in the $X-Y$ plane parallel to the base plane of the workpiece (Fig. 5). The following geometric parameters have been determined:

- $\quad l_{\text {mean }}(h)=\left(l_{1}(h)+l_{\mathrm{r}}(h)\right) / 2$, where $l_{1}(h), l_{\mathrm{r}}(h)$ - distance in the $X$ plane between the leading point of the cutting edge cross-section (point A) to side points of the cutting edges cross-section respectively (points B and C);

- $\quad b(h)$-width of the cutting edge cross-section, distance in the $Y$ plane between points $\mathrm{B}$ and $\mathrm{C}$;

- $o(h)$-length of the cross-section profile between points B and $\mathrm{C}$.

The size of side ridges is influenced by the geometric parameters of the cross-sections of cutting edges of the abrasive grain and abrasive aggregate.

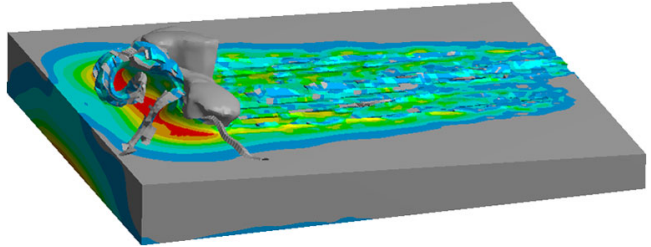

Fig. 4 Visualization of the Ti-6Al-4V alloy cutting with abrasive aggregate 
a

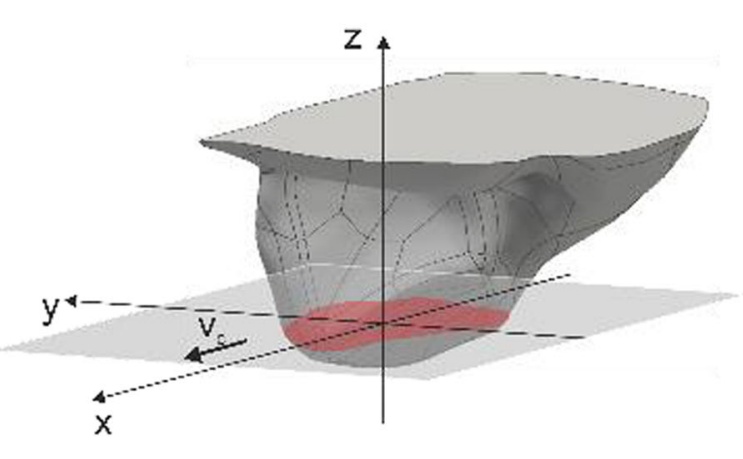

b

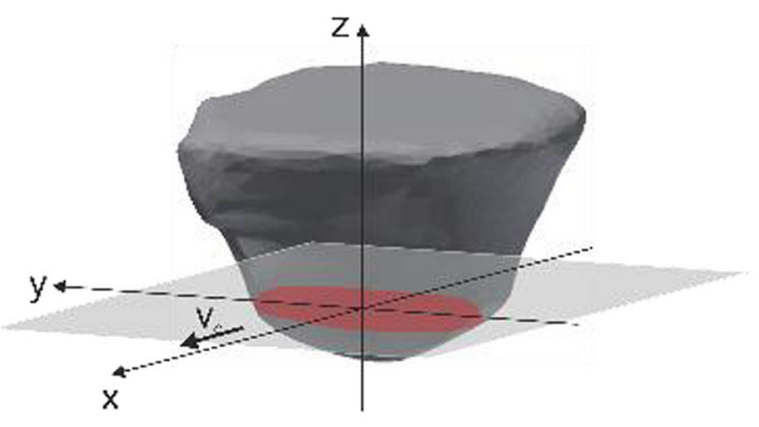

C

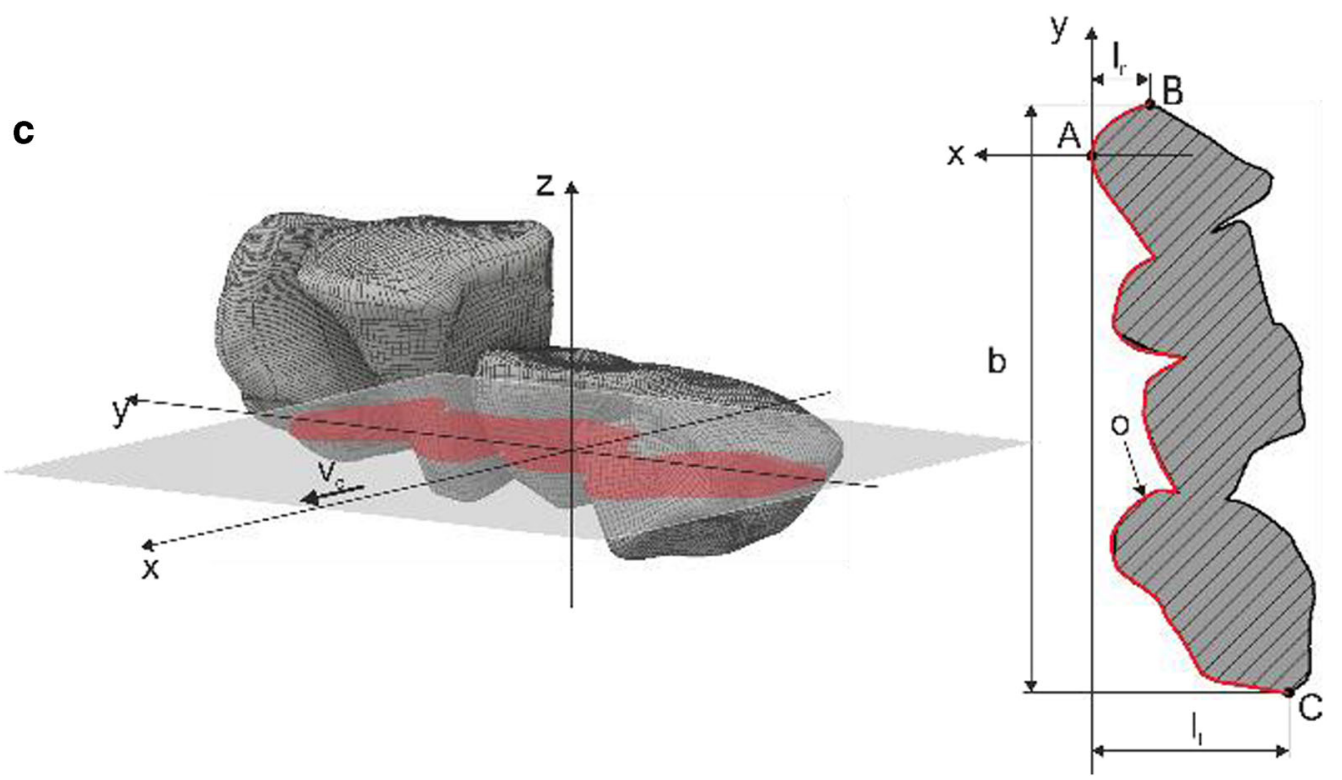

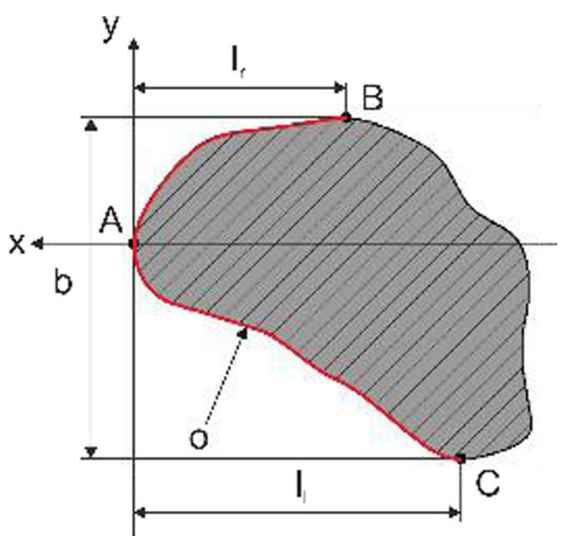

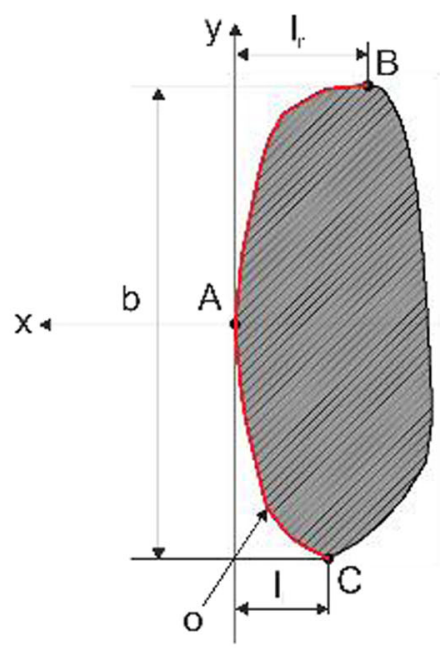

Fig. 5 The scheme for the determination of geometric parameters of abrasive grains $(\mathbf{a}, \mathbf{b})$ and aggregate (c)

For the cutting edges of abrasive grains and abrasive aggregate, the material removal efficiency factor $k_{\mathrm{r}}$ in the function of grain penetration $h$ in the workpiece material was formulated (Fig. 6). Its value is in the range of 0 to 1 . 


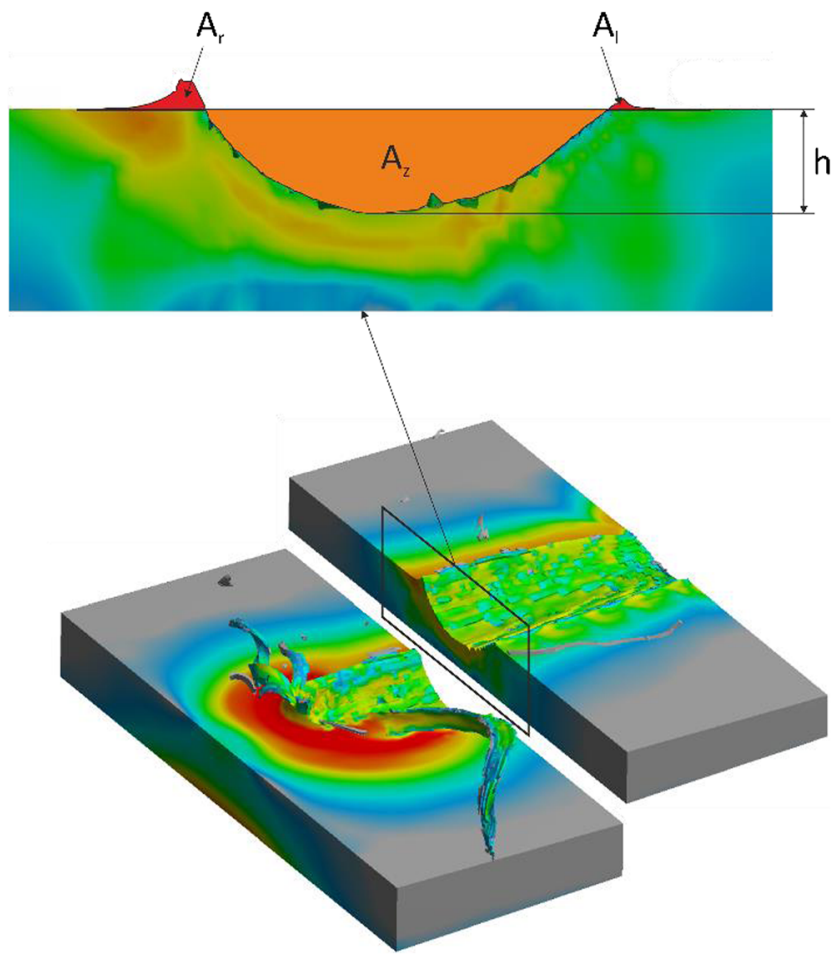

Fig. 6 The scheme for the determination of geometric parameters of single-grain scratches

The value of $k_{r}$ is equal to 1 if the whole material is removed as a chip (the value of cross-section area of side ridges formed on both sides of the cutting edge is equal to 0 ).

$k_{\mathrm{r}}=1-A^{\prime}(h)=1-\frac{A_{1}(h)+A_{\mathrm{r}}(h)}{A_{\mathrm{z}}(h)}$

where $A_{1}(h), A_{\mathrm{r}}(h)$-cross-section area of side ridges formed on both sides of the cutting edge and $A_{\mathrm{z}}(h)$-cross-section area of the material removed by the cutting edge.

An analysis of the geometry characteristics of the abrasive grains and aggregate cross-sections is presented in the Fig. 7.

Grain A is characterized by a sharp open angle (small $b /$ $l_{\text {mean }}$ value) and a small width of the cutting zone $b$. This results in a facilitated lateral flow of the material with less effective microcutting. Grain B and aggregate show much higher values of all geometrical parameters (Fig. 7a-d). For aggregates, these values increase considerably as the penetration in the workpiece material increases when more of the aggregate grains are involved in the cutting. It has been found that the $(o \cdot b) / l_{\text {mean }}^{2}$ factor (Fig. 7d) to a good degree describes the geometry of cutting edges and can be used to evaluate the cutting edge efficiency.

Figure 8 presents a monotonic increasing effect of the cutting edge geometry factor $(o \cdot b) / l_{\text {mean }}^{2}$ on the material removal efficiency factor $k_{\mathrm{r}}$. Grain $\mathrm{B}$ and abrasive aggregate have a higher material removal efficiency factor than grain $\mathrm{A}$. The shape of the grain $\mathrm{B}$ and the aggregate makes the lateral
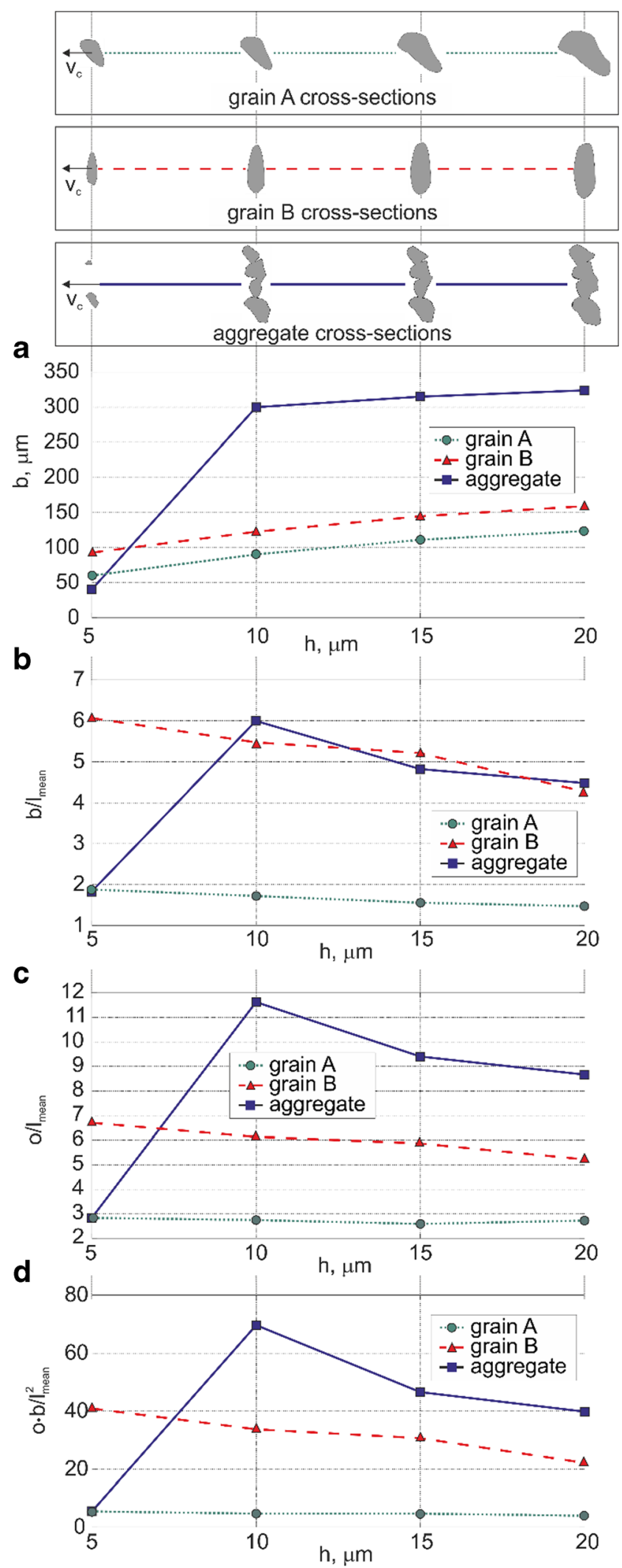

Fig. 7 Influence of the geometric parameters of the abrasive grains and aggregate on width of the cutting zone $b$ (a), ratio of the width of the cutting zone to its length $b / l_{\text {mean }}(\mathbf{b})$, ratio of contact length to cutting zone length $o / l_{\text {mean }}(\mathbf{c})$, and factor $(o \cdot b) / l_{\text {mean }}^{2}(\mathbf{d})$ 


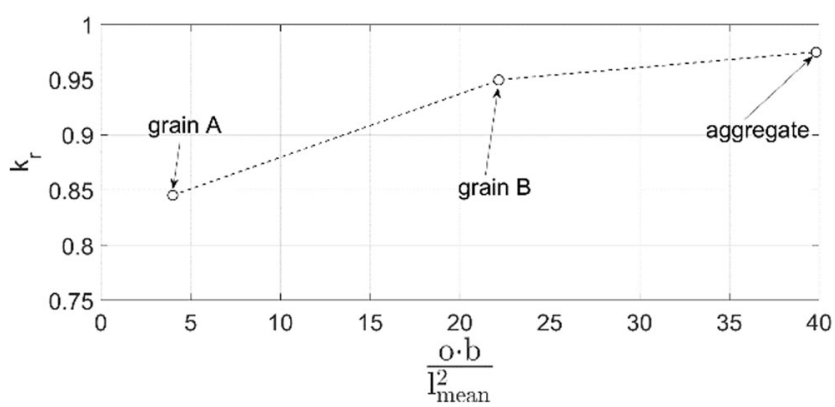

Fig. 8 Influence of the cutting edge geometry factor $(o \cdot b) / l_{\text {mean }}^{2}$ on the material removal efficiency factor $k_{\mathrm{r}}$ for $h=20 \mu \mathrm{m}$

displacements of the material difficult, thereby reducing the size of the side ridges. Abrasive aggregates are characterized by a short distance between the active cutting grains. This influences the restriction of the possibility to produce ridges, which are not formed within the aggregate working zone for greater penetration levels of grains included in the aggregate, but on its rims.

In order to confirm the favourable effect of the abrasive aggregates on the grinding resulting in the reduction of side ridges of the material and thus increase the machining efficiency, an experiment was conducted in accordance to the procedure described in Section 3. Detailed experiment results and their analysis are given below.

\section{Experimental procedure of grinding process with the grinding wheel with abrasive aggregates}

\subsection{Test stand}

In the tests, Ti-6Al-4V alloy samples with the dimension of $80 \mathrm{~mm}(L) \times 20 \mathrm{~mm}(W) \times 13 \mathrm{~mm}(H)$ were used. The chemical composition of the alloy is presented in Table 2. Ti-6Al-4V contains $6 \%$ of aluminium, which stabilizes the alpha phase, and $4 \%$ of vanadium, which stabilizes the beta phase. The addition of aluminium and vanadium improves strength of titanium alloy in low and high temperatures, influences its formability and contributes to oxidation resistance [5, 8]. The mechanical properties of the alloy are presented in Table 3.

The grinding was conducted by using: conventional grinding wheels with aluminium oxide abrasive grains of size F60 (FEPA standards) and grinding wheels modified by addition of F46 size abrasive aggregates consisting of F120 size abrasive grains. The aggregates were distributed evenly
Table 3 Mechanical and chemical properties of the Ti-6Al-4V alloy

\begin{tabular}{ll} 
Tensile strength $(\mathrm{MPa})$ & 993 \\
Yield stress $(\mathrm{MPa})$ & 830 \\
Elongation $(\%)$ & 14 \\
Modulus of elasticity $(\mathrm{GPa})$ & 114 \\
Hardness $(\mathrm{HV})$ & 265 \\
Melting point $\left({ }^{\circ} \mathrm{C}\right)$ & $1538-1649$ \\
Thermal conductivity $(\mathrm{W} / \mathrm{m} \cdot \mathrm{K})$ & 5.44 \\
\hline
\end{tabular}

throughout the grinding wheel volume. As a result of preliminary study, a favourable $30 \%$ contribution by weight of aggregates was determined. Abrasive tools with hardness $\mathrm{K}$ and $\mathrm{M}$ were used, manufactured by Andre Abrasive Articles (Poland).

The parameters of the dressing operation of the grinding wheel active surface and the parameters of grinding process were constant during all the tests. Prior to the experiment, three initial passes were made after the grinding wheel dressing. In the experiment, grinding forces were recorded from one pass. In order to determine repeatability of the obtained results, the tests were conducted three times. The conditions and parameters of the grinding process are presented in Table 4.

During the grinding process, the values of the force components were measured using a piezoelectric dynamometer 9257B and a multi-channel amplifier 5070A12100 by Kistler. The measurement data were registered at $10 \mathrm{kHz}$ frequency using a 16-bit measurement card. After the grinding process, the workpiece surface roughness was analysed. A Talysurf CCI 6000 profilometer by Taylor Hobson was used for the measurement of surface topography. Twenty times magnification lens were used enabling the measurement of a surface with dimensions $0.9 \mathrm{~mm} \times 0.9 \mathrm{~mm}$. To record the data, a CCD sensor with $1024 \times 1024$ resolution was used, which allowed to measure the surface with horizontal resolution of $0.88 \mu \mathrm{m}$. Vertical resolution of the profilometer is up to $10 \mathrm{pm}$. For each of the samples, measurement was conducted three times in random places. The measurement results of each of the analysed samples were averaged. The measurement of the workpiece surface morphology was conducted using a scanning electron microscope (SEM Phenom G2 PRO).

In order to observe the abrasive tool changes during the grinding process, the values of the grinding forces were measured in 100 consecutive grinding passes. After the process was accomplished, the analysis of the grinding wheel wear was performed.

Table 2 Chemical composition of Ti-6Al-4V alloy

\begin{tabular}{llllllllll}
\hline Content & $\mathrm{C}(\max )$ & $\mathrm{Fe}(\max )$ & $\mathrm{N}(\max )$ & $\mathrm{O}(\max )$ & $\mathrm{Al}$ & $\mathrm{Si}(\max )$ & $\mathrm{V}$ & $\mathrm{H}(\max )$ & $\mathrm{Ti}$ \\
\hline Composition (wt\%) & 0.1 & 0.3 & 0.05 & 0.15 & $5.5-6.8$ & 0.15 & $3.5-4.5$ & 0.015 & Balance \\
\hline
\end{tabular}


Table 4 Conditions and parameters of the grinding process

\begin{tabular}{|c|c|}
\hline Grinding mode & Plunge surface grinding, down cut \\
\hline Grinding wheel & $\begin{array}{l}\text { Grinding wheel } 0 \mathrm{~K} \text { (hardness } \mathrm{K}, 0 \% \text { aggregates) } \\
\text { Grinding wheel } 30 \mathrm{~K} \text { (hardness } \mathrm{K}, 30 \% \text { aggregates) } \\
\text { Grinding wheel } 0 \mathrm{M} \text { (hardness } \mathrm{M}, 0 \% \text { aggregates) } \\
\text { Grinding wheel } 30 \mathrm{M} \text { (hardness } \mathrm{M}, 30 \% \\
\quad \text { aggregates) }\end{array}$ \\
\hline Grinding machine & Surface grinder JOTES SPC-20B \\
\hline Wheel speed $\left(v_{\mathrm{c}}\right)$ & $v_{\mathrm{c}}=30 \mathrm{~m} / \mathrm{s}$ \\
\hline Work speed $\left(v_{\mathrm{w}}\right)$ & $v_{\mathrm{w}}=25 \mathrm{~m} / \mathrm{min}$ \\
\hline Depth of cut (DOC) & $a_{\mathrm{p}}=5,10,20 \mu \mathrm{m}$ \\
\hline Environments & Wet grinding \\
\hline $\begin{array}{r}\text { Workpiece } \\
\text { material }\end{array}$ & Ti-6Al-4V $(80 \mathrm{~mm} \times 13 \mathrm{~mm} \times 20 \mathrm{~mm})$ \\
\hline Dresser & Single-point diamond dresser \\
\hline Dressing depth $\left(a_{\mathrm{d}}\right)$ & Total depth of dressing $a_{\mathrm{d}}=0.05 \mathrm{~mm}$ \\
\hline ressing speed $\left(v_{\mathrm{d}}\right)$ & $v_{\mathrm{d}}=5 \mathrm{~mm} / \mathrm{s}$ \\
\hline
\end{tabular}

\section{Results and discussion}

\subsection{Grinding force and specific energy}

The intensity of heat generation in the grinding zone depends on the values of grinding forces and is of particular importance in reference to these processing types, in which surface quality without thermal damages is significant [28]. Forces $F$ occurring in the analysed grinding process can be decomposed into the following: tangential grinding force $F_{\mathrm{t}}$ and normal grinding force $F_{\mathrm{n}}$.

$F=F_{\mathrm{t}}+F_{\mathrm{n}}$

The values of the normal and tangential grinding force referred to the width of grinding zone $b$ are presented in Figs. 9 and 10.

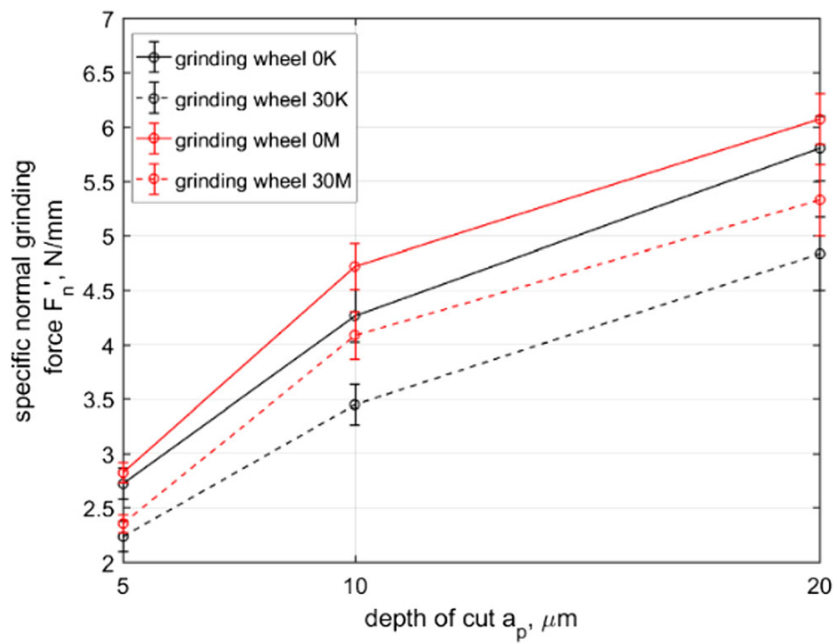

Fig. 9 Influence of the grinding depth on the value of the normal grinding force $F_{\mathrm{n}}$ ' in the grinding process using the conventional grinding wheel and the grinding wheel with $30 \%$ contribution of abrasive aggregates with hardness $\mathrm{K}$ and $\mathrm{M}$

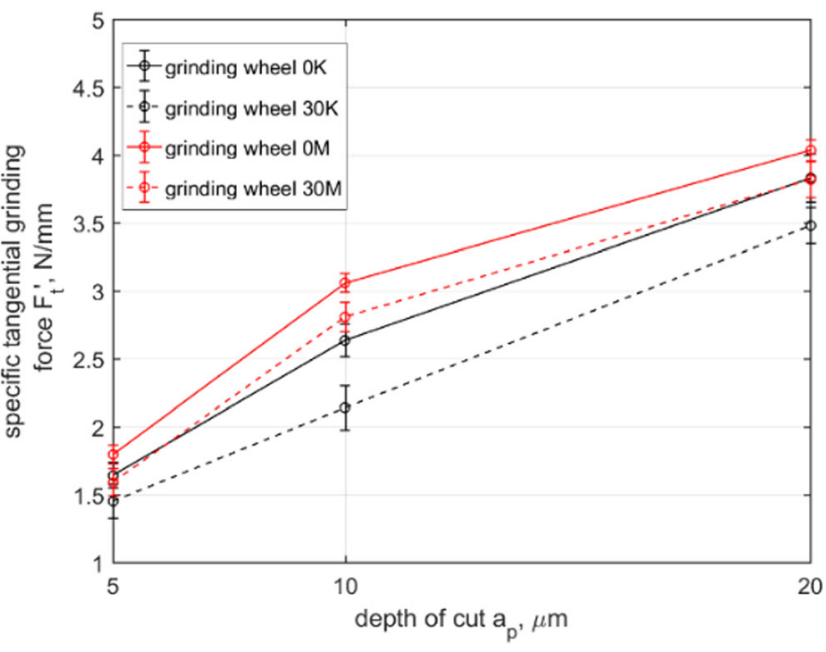

Fig. 10 Influence of the grinding depth on the value of the tangential grinding force $\mathrm{F}_{\mathrm{t}}{ }_{\mathrm{t}}$ in the grinding process using the conventional grinding wheel and the grinding wheel with $30 \%$ contribution of abrasive aggregates with hardness $\mathrm{K}$ and $\mathrm{M}$

Figures 9 and 10 present the variability of the respective values of the normal and tangential grinding forces for different grinding wheels depending on the depth of cut. In all cases, an increase of the value of the grinding force is visible. The increase of the depth of cut increases the value of the penetration of active grains in the processed material and the area of chips cross-section. A decrease of the values of grinding force components in the grinding wheels with aggregates as compared to conventional grinding wheels stems from, i.a., the specific fracturing process of grains and aggregate. The binder in the aggregate is characterized by lower strength than the binder between aggregates and basic abrasive grains, which causes the external grains in the aggregate to be better established, whereas the internal weaker. In effect, microcavities are being formed in aggregates, locally increasing porosity and reducing cutting resistance. Moreover, a significant role in the reduction of the values of the grinding force components is being played by the different character of interactions of the abrasive aggregate with the workpiece in comparison to the character of interactions of a single abrasive grain.

The relation of values of specific grinding forces $F_{\mathrm{t}}{ }^{\prime}$ and $F_{\mathrm{n}}{ }^{\prime}$ and the depth of cutting for the analysed abrasive tools is presented in Fig. 11.

Along with the increase of the grinding depth, an increase of the ratio of specific grinding forces $F_{\mathrm{t}}{ }^{\prime} / F_{\mathrm{n}}$ ' can be observed. This state stems from the changes of the interactions in the cutting zone, taking place along with the change of abrasive grain penetration in the workpiece. Elastic deformations dominate in the small depth of cuts in the processing zone. In this zone, the abrasive grain is rubbing or sliding on the workpiece. When the depth of cut increases (ploughing stage), the abrasive grain penetrates into the workpiece and causes 


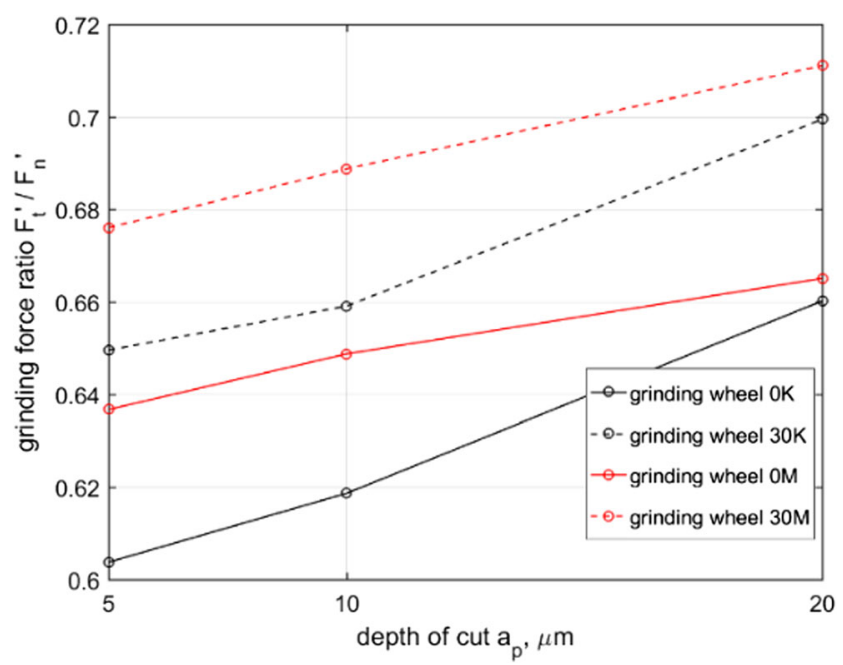

Fig. 11 Influence of the grinding depth on the value of grinding force coefficient in the grinding process using the conventional grinding wheel and the grinding wheel with $30 \%$ contribution of abrasive aggregates with hardness $\mathrm{K}$ and $\mathrm{M}$

the material to shift in front of the grain and to the sides, creating ridges on the sides of the scratch formed by the grain. In the next stage (cutting stage), the material moves in front of the abrasive grain and is separated in the form of a chip. An increment of the grinding force ratio occurs as a result of the increase of contribution of the chip formation process in material removal process.

Figure 11 presents an increased value of the specific grinding force ratio for grinding wheels with aggregates in comparison with that for the conventional grinding wheels. This stems from the more efficient process of material removal in the cutting zone of the abrasive aggregate. Abrasive aggregates consist of grains smaller than basic grains, thus grains with smaller sizes and radii of the cutting edges. This causes the formation of two contradictory results of interactions in the contact area of abrasive aggregate with the workpiece. On the one hand, the specific energy for the small cross-sections of the cut layers is greater than that for the large cross-sections. On the other hand, as a result of high grain density in abrasive

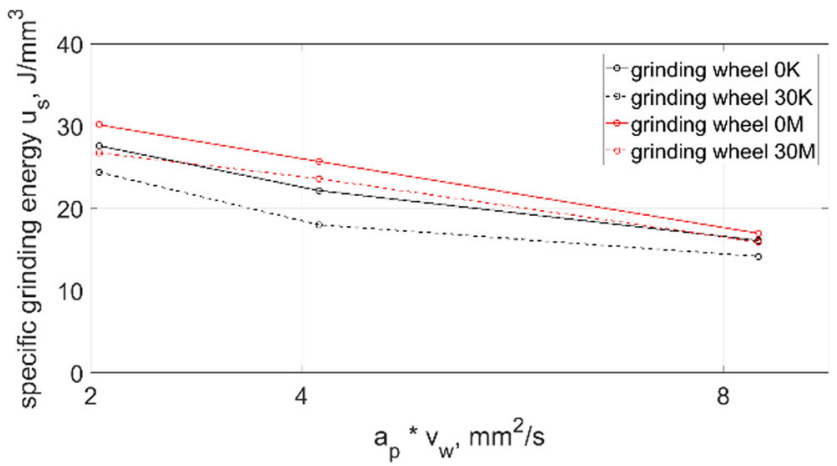

Fig. 12 Influence of the grinding process parameters on the specific energy for conventional grinding wheels and aggregate grinding wheels with hardness $\mathrm{K}$ and $\mathrm{M}$

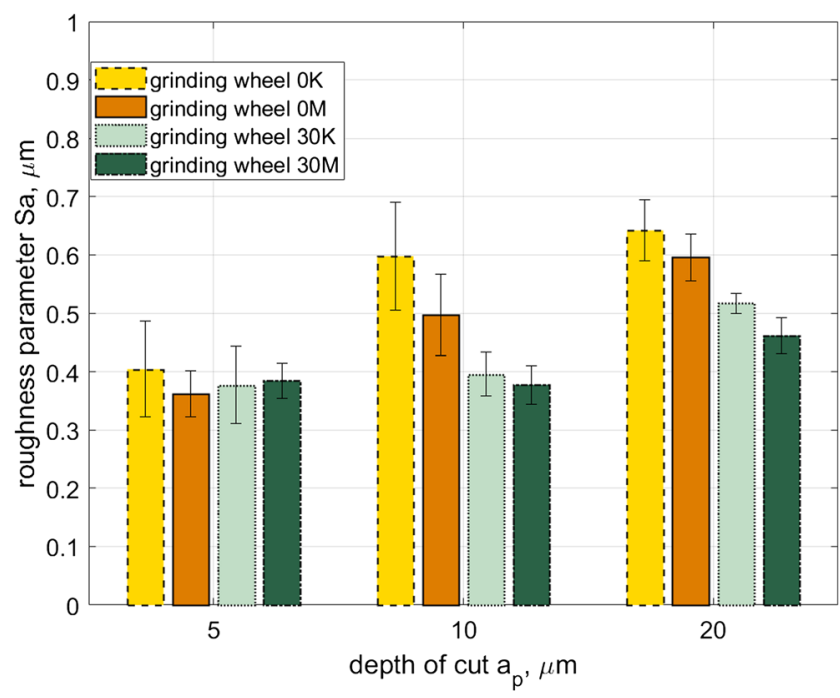

Fig. 13 Comparison of the influence of depth of cut on the value of roughness parameter $S \mathrm{a}$ of the surface processed with the conventional grinding wheel and the grinding wheel with a $30 \%$ contribution of agglomerates

aggregate, the total number of active blades on its surface cut layers with a large width. As an effect, the lateral movement of the material is inhibited in the cutting zone of abrasive aggregate; thus, the contribution of elastic deformations is lower and the chip separation process is more efficient. This influences reduction of the specific energy of the grinding process.

The specific energy of the grinding process is the parameter that enables the evaluation of abrasive tools. Specific energy $u_{\mathrm{s}}$ of the grinding process can be expressed using the following equation:

$u_{\mathrm{s}}^{\prime}=F_{\mathrm{t}}^{\prime} \frac{v_{\mathrm{s}}}{v_{\mathrm{w}} \times a_{\mathrm{p}}}$

The influence of grinding parameters for different abrasive tools on the grinding-specific energy is presented in Fig. 12.

Figure 12 presents reduction of the specific energy of grinding in which the grinding wheels with aggregates are used. This means that the results of energy reduction stemming from the decrease of side ridges of the material are greater than the results of the specific energy increment stemming from the increased contribution of smaller cross-sections of the cut layers.

\subsection{Surface roughness and surface morphology}

The processed samples were subjected to roughness analysis by the measurement in three randomly selected areas on the surface. For the measured surface areas, the values of roughness parameter $S$ a were calculated. A comparison of the roughness parameters of the ground surfaces with conventional grinding wheel of hardness $\mathrm{K}$ and $\mathrm{M}$ and grinding wheel with $30 \%$ contribution of aggregates of hardness $\mathrm{K}$ and $\mathrm{M}$ was performed (Fig. 13). 
Fig. 14 SEM image of the ground surface $\left(a_{\mathrm{p}}=20 \mu \mathrm{m}\right)$ with the conventional grinding wheel of hardness K (a) and with the grinding wheel of hardness $\mathrm{K}$ with $30 \%$ addition of abrasive agglomerates (b)
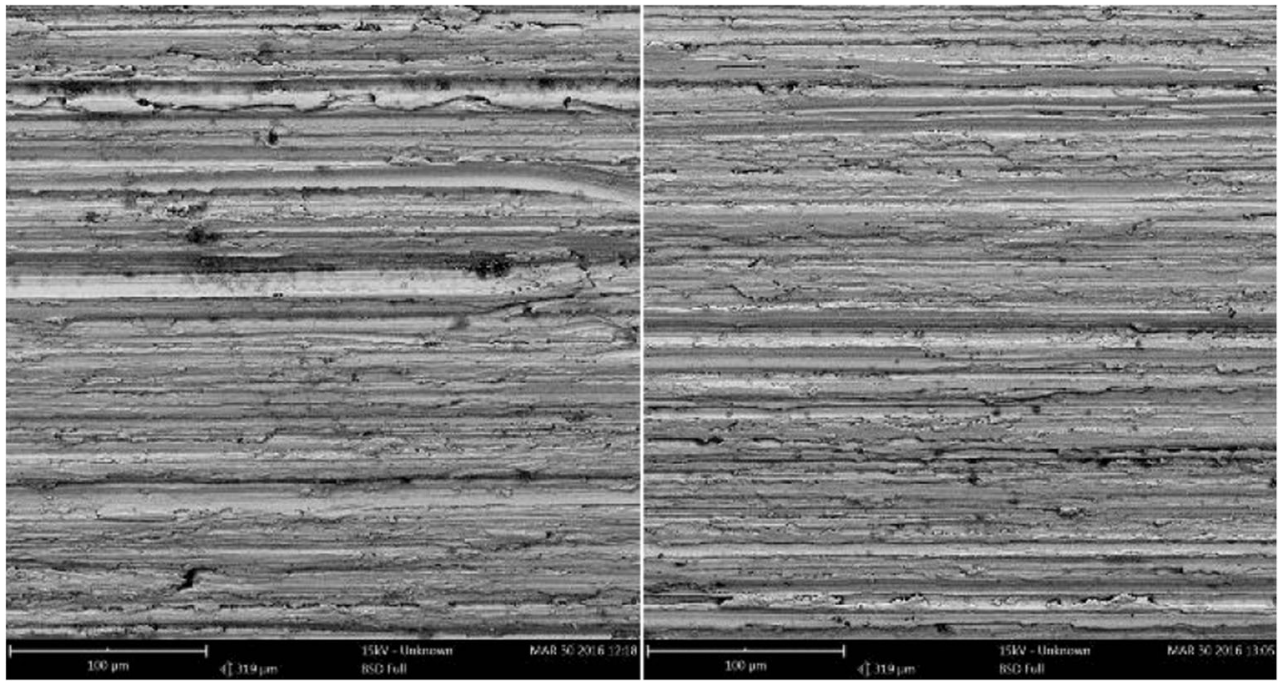

Figure 13 presents a decreased value of roughness parameter $S$ a of the surface processed with the agglomerate grinding wheel as compared to that with the conventional grinding wheel. Lower values of the roughness parameter stem from the favourable mechanism of material separation occurring for abrasive aggregates, causing a lower number of side ridges. Moreover, this results in a lower variability of the roughness parameters. The positive influence of abrasive aggregates decreases with the decrease of depth of cut to $5 \mu \mathrm{m}$. The cause may stems from smaller cross-sections of the abrasive grains, which, instead of removing the material, performs solely rubbing and ploughing.

The visual evaluation of the samples did not find cracks, burns or signs of vibrations on the processed surface. The images of the processed surface obtained using SEM are presented in Figs. 14 and 15.

SEM image of the processed surface shows explicit features, including smooth areas, scratches and material ridges.
Scratches are visible in the form of cutting marks, formed by the active grains, and grooves, resulting from the penetration of crumbled grain fragments or entire abrasive grains into the material. Smooth areas visible on the ground surface result from interaction of abrasive aggregates having wide cutting zone and small distance between the active blades.

\subsection{Grinding wheel wear and grinding ratio}

In order to analyse changes of the influence of the grinding wheel active surface with the workpiece in time, an analysis of the normal grinding force was performed in 100 subsequent grinding passes. Grinding width $b$ was $10 \mathrm{~mm}$, and the depth of cut per single pass was $20 \mu \mathrm{m}$. The remaining grinding parameters corresponded to the parameters determined in Table 4.

The specific normal grinding force presented in Fig. 16 for the grinding wheel of hardness $\mathrm{K}$ indicates a stable process. In
Fig. 15 SEM image of the ground surface $\left(a_{\mathrm{p}}=20 \mu \mathrm{m}\right)$ with the conventional grinding wheel of hardness M (a) and with the grinding wheel of hardness $M$ with $30 \%$ addition of abrasive agglomerates (b)
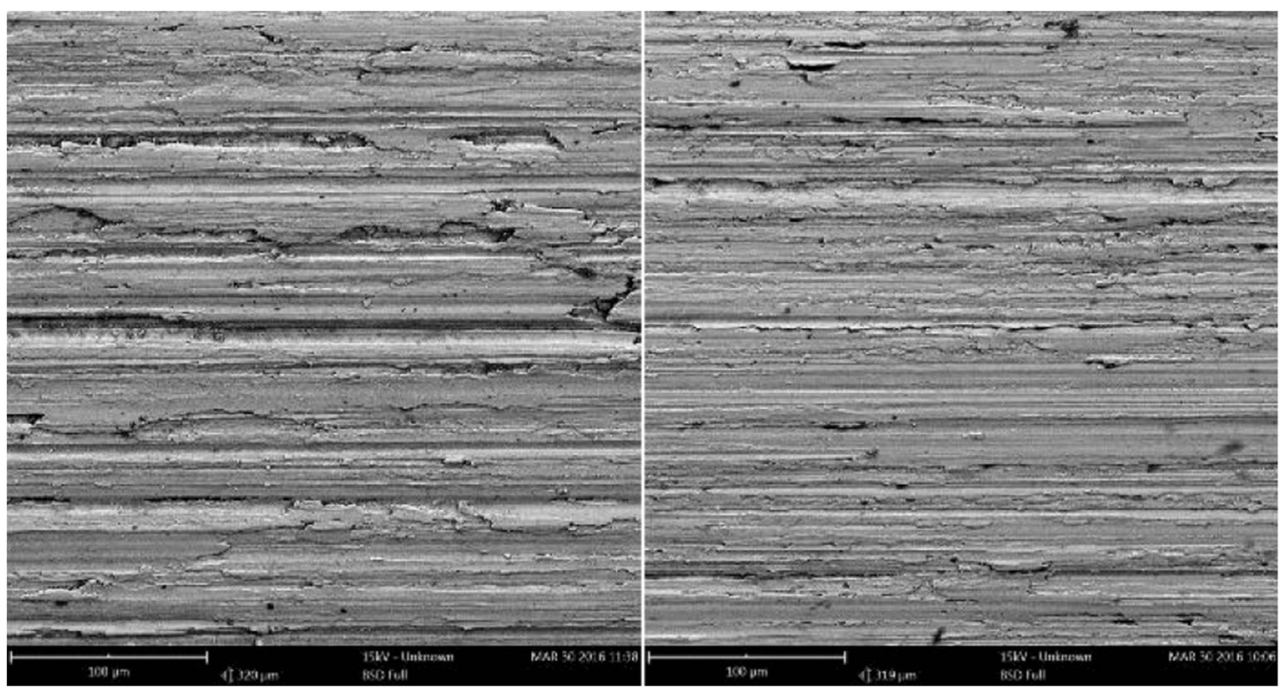


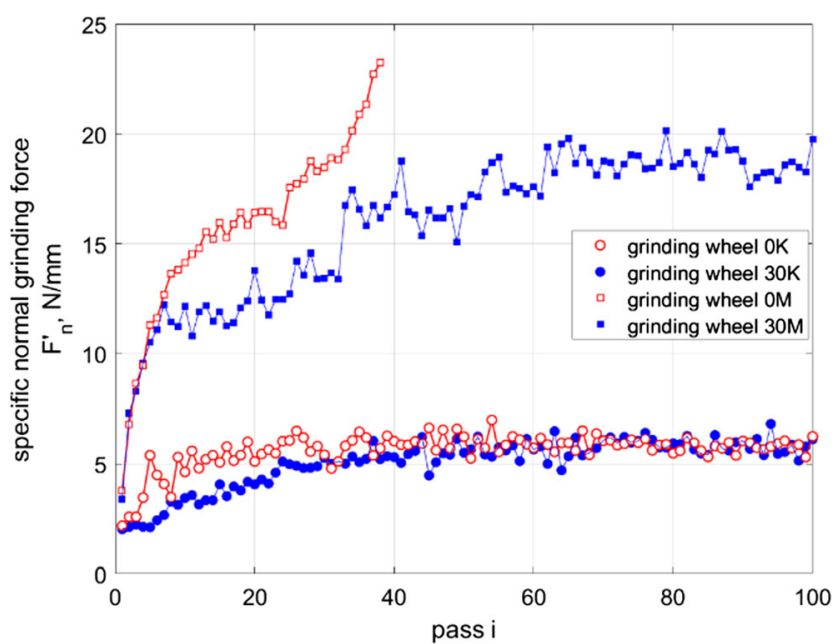

Fig. 16 Specific normal grinding force in subsequent passes of grinding for grinding wheels of hardness $\mathrm{K}$ and $\mathrm{M}$

the case of the grinding wheel of hardness $\mathrm{M}$, the increase of grinding forces stemming from the abrasion of the abrasive grain vertices and loading up of the grinding wheel active surface is clearly visible. In the case of the process being conducted with the use of the grinding wheel of hardness M without aggregates, the process was stopped after 38 passes due to the loss of cutting ability of the abrasive tool.

The analysis of the grinding wheel active surface was conducted using a scanning microscope. Example SEM images of the grinding wheel active surface are presented in Figs. 17 and 18.

The microfractures of vertices of the active grains and fractures of the active grains and bonds are visible on the grinding wheel active surface of hardness M (Fig. 17a, b). Numerous fragments of abrasive grains were found in the intergranular spaces. An increase of the contact area of the grinding wheel with the workpiece is a result of microfractures of abrasive grains and loading up in the intergranular spaces. As a result, an increase of the value of the specific normal grinding force took place (Fig. 16).

In the case of grinding with the grinding wheel of hardness $M$ with the addition of abrasive aggregates, a smaller increase of the value of the specific normal grinding force is observed.
Fig. 17 SEM image of the grinding wheel active surface of the conventional grinding wheel of hardness $\mathrm{M}(\mathbf{a}, \mathbf{b})$ and the grinding wheel of hardness $M$ with $30 \%$ addition of abrasive agglomerates (c, d)
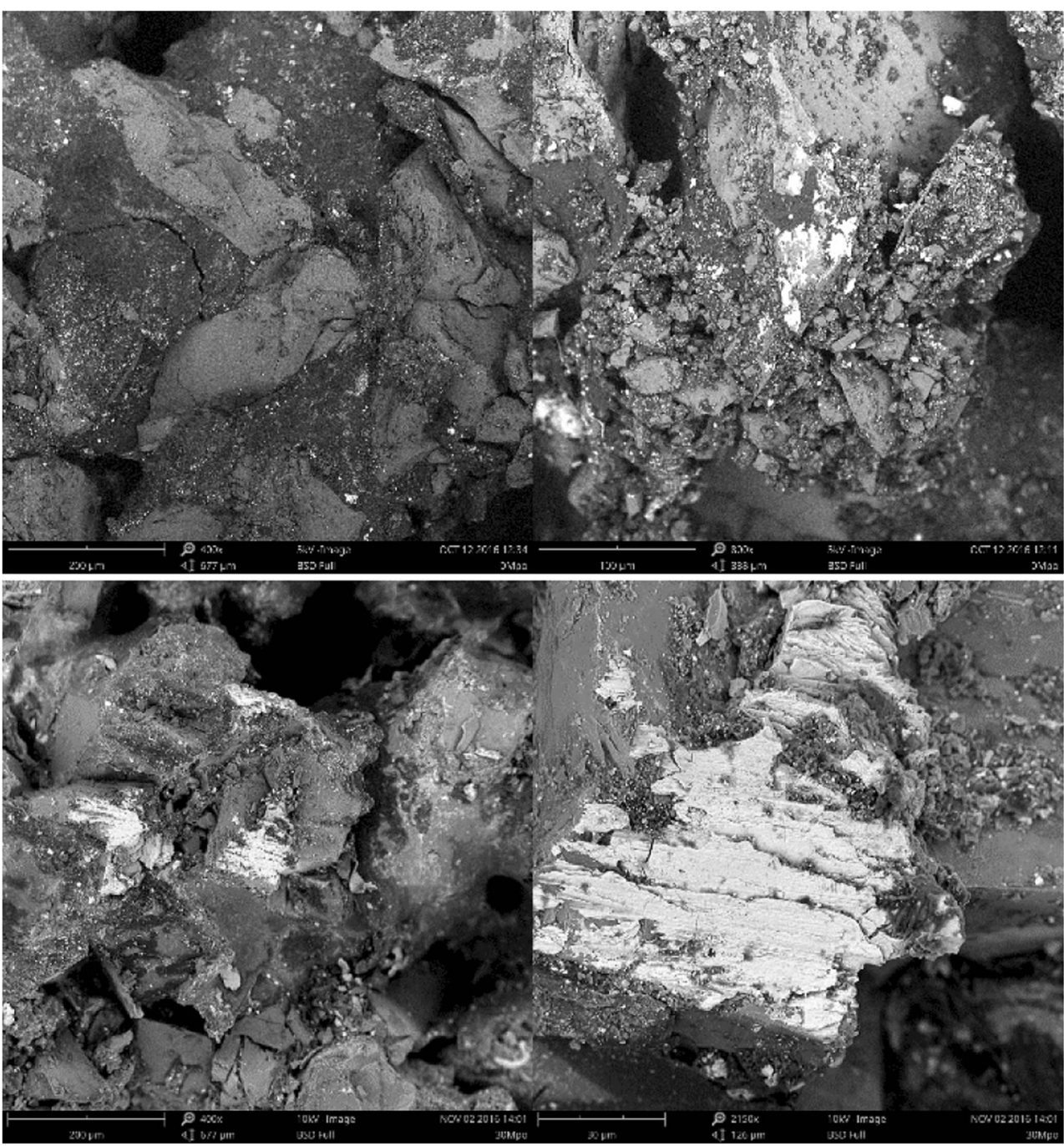
Fig. 18 SEM image of the grinding wheel active surface of the conventional grinding wheel of hardness $\mathrm{K}(\mathbf{a}, \mathbf{b})$ and the grinding wheel of hardness $\mathrm{K}$ with $30 \%$ addition of abrasive agglomerates (c, d)
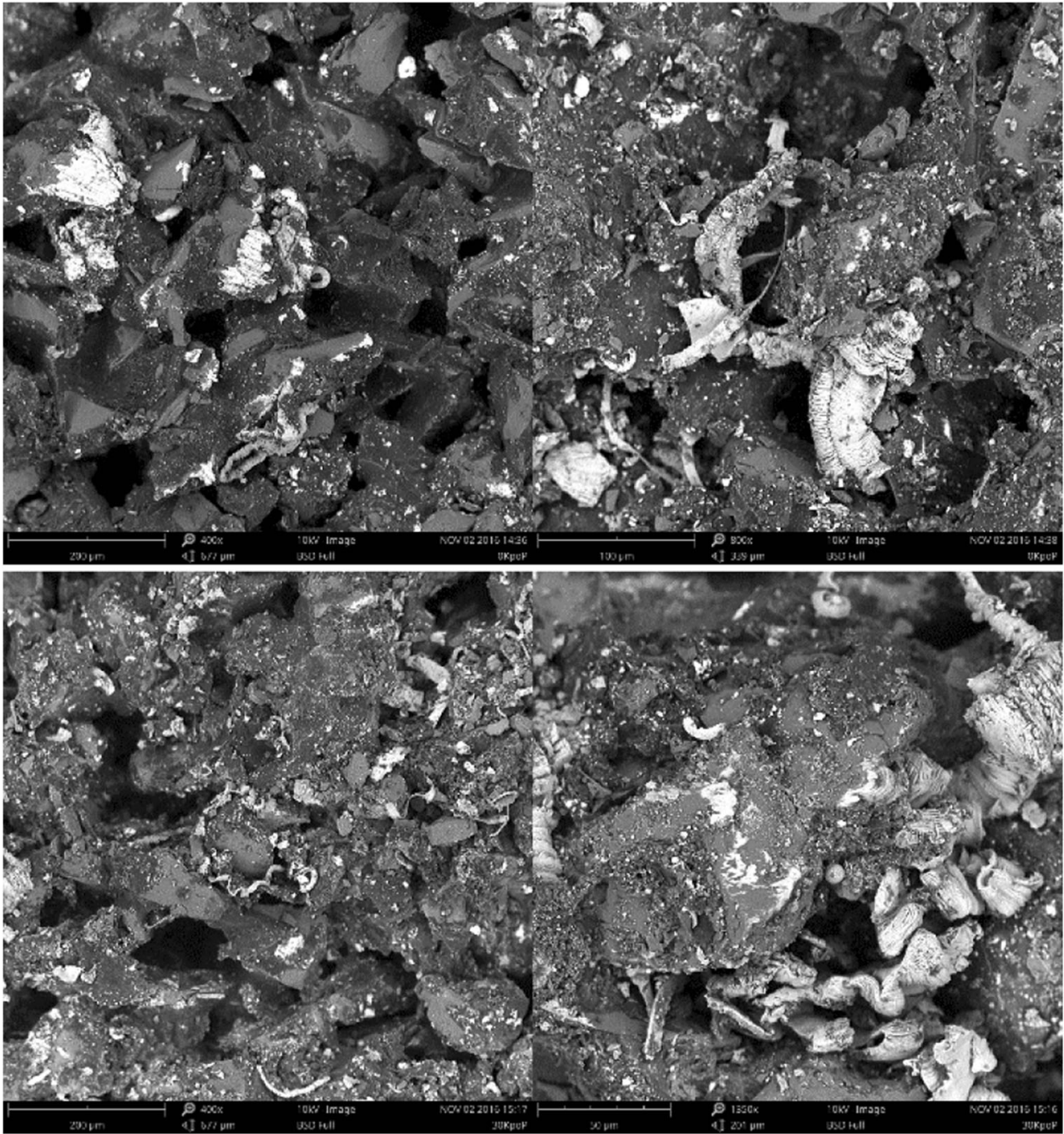

The increase of the specific normal grinding force is primarily caused by the abrasion of the vertices of the abrasive grains and the increased contact area of the active grains with the workpiece, taking place as a result of adhesion of the material to vertices of these grains. The increase of the contact area of the abrasive tool with the workpiece leads to the fractures of the abrasive grains, primarily of these included in abrasive aggregates. This results in a more open structure of the abrasive tool, decreased susceptibility to loading up and thus, a longer life as compared to that of abrasive tools without abrasive aggregates.

The grinding wheel active surface of hardness $\mathrm{K}$ was presented in Fig. 18. Numerous abrasive grains break-off are visible. In the case of a conventional grinding wheel, more numerous abrasions of abrasive grain vertices are observed than those in the case of the grinding wheel with abrasive aggregates. During the grinding the course of the specific grinding normal force is of similar character for both abrasive tools. Moreover, the course of the specific normal grinding force indicates that during the process a strong selfsharpening of the abrasive tool took place. Grinding ratio $G$ for the conventional grinding wheel with a hardness $\mathrm{K}$ was 0.4 , and the grinding wheel with abrasive aggregates was 0.43 . Radial wear of the grinding wheels with hardness $\mathrm{K}$ was almost twofold higher than that of the grinding wheel with hardness M. The value of grinding ratio $G$ for the grinding wheel with hardness $M$ with abrasive aggregates was 0.86 . The value of grinding ratio for conventional grinding wheel with hardness $\mathrm{M}$ was not determined due to lost the cutting ability of the grinding wheel after 38 passes.

\section{Conclusion}

As a result of the conducted experimental study and numerical analyses of the grinding process of Ti-6Al-4V alloy with the conventional grinding wheels and the grinding wheels containing aggregates, it can be stated that:

- The use of the grinding wheels with aggregates to grind Ti$6 \mathrm{Al}-4 \mathrm{~V}$ alloy enables to obtain a favourable course of the 
grinding process, stemming from stable working conditions along the trajectory of individual abrasive aggregates.

- The use of the grinding wheels with aggregates for the grinding of Ti-6Al-4V alloy significantly increases the efficiency of material removal process. Abrasive aggregates have favourable geometric parameters, which significantly increase the width of the contact area and thus hinder the side flow of the material and the formation of ridges.

- The factor $(o \cdot b) / l_{\text {mean }}^{2}$ allows to determine the material removal efficiency of the abrasive grain. The greater the value of this factor, the smaller the side ridges on the workpiece material.

- The grinding process with the grinding wheel containing abrasive aggregates is characterized by lower values of the grinding forces and grinding energy obtained as a result of an efficient microsharpening and the formation of microcavities on the surface of abrasive aggregates.

- The use of $30 \%$ contribution of abrasive aggregates enables to obtain the processed surface with lower value of surface roughness parameter $\mathrm{Sa}$ as compared to the surface roughness obtained through grinding with a conventional grinding wheel.

- The use of grinding wheels with abrasive aggregates allows to reduce the increase of grinding forces with the time of processing, therefore increasing the abrasive tool life.

Acknowledgments The authors would like to thank Joanna Wieczyńska, MSc from the International Cooperation Office of Koszalin University of Technology for manuscript proofreading. Funding This study was funded by the National Center for Research and Development of the Polish Republic (grant no. INNO-TECH-K3/ IN3/43/229135/NCBR/14).

\section{Compliance with ethical standards}

Conflict of interest The authors declare that they have no conflict of interest.

Open Access This article is distributed under the terms of the Creative Commons Attribution 4.0 International License (http:// creativecommons.org/licenses/by/4.0/), which permits unrestricted use, distribution, and reproduction in any medium, provided you give appropriate credit to the original author(s) and the source, provide a link to the Creative Commons license, and indicate if changes were made.

\section{References}

1. Pramanik A (2004) Problems and solutions in machining of titanium alloy. Int J Adv Manuf Technol 70:919-928. doi:10.1007/ s00170-013-5326-x

2. Ezegwu WO, Bonney J, Yamane Y (2003) An overview of the machinability of aeroengine alloys. J Mater Process Technol 134: 233-253. doi:10.1016/S0924-0136(02)01042-7
3. Ulutan D, Ozel T (2011) Machining induced surface integrity in titanium alloy and nickel alloy: a review. Int J Mach Tools Manuf 51:250-280. doi:10.1016/j.ijmachtools.2010.11.003

4. Gurrappa I (2003) Characterization of titanium alloy Ti-6Al-4V for chemical, marine and industrial applications. Mater Charact 51: 131-139. doi:10.1016/j.matchar.2003.10.006

5. Ezogwu EO, Wang ZM (1997) Titanium alloy and their machinability - a review. J Mater Process Technol 68:262-274. doi:10. 1016/S0924-0136(96)00030-1

6. Moiseev VN (2004) Structural titanium alloy in modern mechanical engineering. Metal Science and Heat Treatment 46(3):115-120. doi:10.1023/B:MSAT.0000036661.85738.62

7. Xu XP, Yu YQ, Huang H (2003) Mechanisms of abrasive wear in the grinding of titanium (TC4) and nickel (K417) alloys. Wear 255(7-12):1421-1426. doi:10.1016/S0043-1648(03)00163-7

8. Guo G, Liu Z, An Q (2011) Experimental investigation on conventional grinding of $\mathrm{Ti}-6 \mathrm{Al}-4 \mathrm{~V}$ using $\mathrm{SiC}$ abrasive. International Journal of Advanced Manufacturing Technology 57:135-142

9. Zoya ZA, Krishnamurthy R (2000) The performance of CBN tools in the machining of titanium alloys. J Mater Process Technol 100: 80-86. doi:10.1016/S0924-0136(99)00464-1

10. Teicher U, Ghosh A, Chattopadhyay AB, Künanz K (2005) On the grindability of titanium alloy by brazed type monolayered superabrasive grinding wheels. Int J Mach Tools Manuf 46:620622. doi:10.1016/j.ijmachtools.2005.07.012

11. Pramanik A, Islam MN, Basak A, Littlefair G (2013) Machining and tool wear mechanisms during machining titanium alloys. Adv Mater Res 651:338-343. doi:10.4028/www.scientific.net/AMR. 651.338

12. Arrazola PJ, Özel T (2010) Investigations on the effects of friction modeling in finite element simulation of machining. International Journal of Mechanical Science 52(1):31-42. doi:10.1016/j. ijmecsci.2009.10.001

13. Arulkirubakaran D, Senthilkumar V, Kumawat V (2016) Effect of micro-textured tools on machining of Ti-6Al-4V alloy: an experimental and numerical approach. Int J Refract Met Hard Mater 54: 165-177. doi:10.1016/j.ijrmhm.2015.07.027

14. Zoya ZA, Krishnamurthy R (2000) The performance of CBN tools in the machining of titanium alloys. Journal of Materials Processing Technology 100(1-3):80-86. doi:10. 1016/S0924-0136(99)00464-1

15. Kalita P, Malshe AP, Kumar SA, Yoganath VG, Gurumurthy T (2012) Study of specific energy and friction coefficient in minimum quantity lubrication grinding using oil-based nanolubricants. J Manuf Process 14:160-166. doi:10.1016/j.jmapro.2012.01.001

16. Sadeghi MH, Haddad MJ, Tawakoli T, Emami M (2009) Minimal quantity lubrication-MQL in grinding of Ti-6 $\mathrm{Al}-4 \mathrm{~V}$ titanium alloy. Int J Adv Manuf Technol 44:487-500. doi:10.1007/s00170-008$1857-y$

17. Tawakoli T, Hadad MJ, Sadeghi MH, Daneshi A, Stöckert S, Rasifarda A (2009) An experimental investigation of the effects of workpiece and grinding parameters on minimum quantity lubrication-MQL grinding. Int J Mach Tools Manuf 49:924-932. doi: 10.1016/j.ijmachtools.2009.06.015

18. I.D. Marinescu, M. Hitchiner, E. Uhlmann, W.B. Rowe, I. Inasaki (2007) Handbook of Machining with Grinding Wheels, CRC Press, Taylor \& Francis Group, Boca Raton

19. S. Malkin, C. Guo (2008) Grinding technology - theory and applications of machining with abrasives, Industrial Press Inc., New York

20. Hahn RS (1966) On the mechanics of the grinding process under plunge cut conditions. Journal of Engineering for Industry 88(1): 72-79. doi:10.1115/1.3670895

21. Axinte D, Butler-Smith P, Akgun C, Kolluru K (2013) On the influence of single grit micro-geometry on grinding behavior of 
ductile and brittle materials. Int J Mach Tools Manuf 74:12-18. doi: 10.1016/j.ijmachtools.2013.06.002

22. Rasim M, Mattfeld P, Klocke F (2015) Analysis of the grain shape influence on the chip formation in grinding. J Mater Process Technol 226:60-68. doi:10.1016/j.jmatprotec.2015.06.041

23. Lipiński D, Kacalak W, Tomkowski R (2014) Methodology of evaluation of abrasive tool wear with the use of laser scanning microscopy. Scanning 36(1):53-63. doi:10.1002/sca.21088

24. Lipiński D, Kacalak W (2016) Metrological aspects of abrasive tool active surface topography evaluation. Metrology and Measurement Systems 23(4):567-577. doi:10.1515/mms-2016-0043

25. Johnson GR, Cook WH (1983) A constitutive model and data for metals subjected to large strains, high strain-rate, and temperatures.
Proceedings of the 7th International Symposium on Ballistics 54:17

26. Buchkremer S, Wu B, Lung D, Münstermann S, Klocke F, Bleck W (2014) FE-simulation of machining processes with a new material model. J Mater Process Technol 214(3):599-611. doi:10.1016/j. jmatprotec.2013.10.014

27. Sima M, Özel T (2010) Modified material constitutive models for serrated chip formation simulations and experimental validation in machining of titanium alloy Ti-6Al-4V. Int J Mach Tools Manuf 50(11):943-960. doi:10.1016/j.ijmachtools.2010.08.004

28. Reddy NSK, Rao PV (2006) Experimental investigation to study the effect of solid lubricants on cutting forces and surface in end milling. International Journal of Machine Tool and Manufacture 46(2):189-198. doi:10.1016/j.jimachtools.2005.04.008 